apuntesuniversitarios.upeu.edu.pe

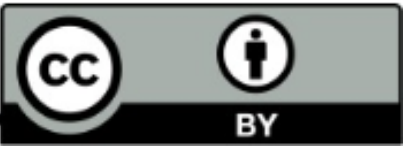

Apuntes Universitarios, 2020: 10(1), Enero-Marzo

ISSN: 2304-0335 DOI: https://doi.org/10.17162/au.v10i1.445

\title{
RECENSIÓN
}

\author{
Edgar Gutiérrez Gómez ${ }^{1 *}$ \\ Universidad Nacional Autónoma de Huanta-Perú ${ }^{1}$ \\ https://orcid.org/0000-0001-9485-1284
}

\section{Rosa María Palacios, Augusto Álvarez Rodrich, Juan Carlos Tafur (2017). Fuera del aire. Lima: Editorial Planeta Perú S. A. 179 pp.}

La historia de la política peruana está impregnada de populismos extremos y moderados, con poca objetividad de la situación nacional. Los medios de comunicación compiten con un papel importante desde los orígenes de la república: "Sin embargo, en sociedades como la peruana, existen indicios de un uso soterrado de técnicas de propaganda por parte de los medios de comunicación" (Hinojosa, 2014, p. 262). Esta propaganda se encuentra vigente en regímenes democráticos y autoritarios, con sus operadores de censura y agentes de prensa. Bajo este contexto, se articula muy bien el trabajo dialogado de Rosa María Palacios, Augusto Álvarez Rodrich y Juan Carlos Tafur en el libro titulado Fuera del aire, que explora-al estilo de Diálogos de Platón - la situación de la prensa actual y su influencia en las decisiones políticas. Esta publicación se divide en nueve capítulos precisos para su comprensión crítica de los puntos de vista que abordan. Además, interpelan sus experiencias personales en los trabajos periodísticos desde sus primeras etapas de iniciación periodística personal, con un trabajo para empresarios que no tienen profesión de periodistas, sino propietarios de empresas informativas del Perú y sus desavenencias constantes con el término que fueron botados, casi con la misma experiencia en los tres autores del libro Fuera del aire.

En el primer capítulo titulado “Todo tiene un inicio: ¿por qué periodista?”, Álvarez Rodrich origina una referencia sobre el trabajo periodístico a la obra de Vargas Llosa La crónica

\footnotetext{
*Email: egutierrez@unah.edu.pe
} 
de conversación en La Catedral: "Un trabajo con mucha diversión, pero también con mucho trago, putas, vida desordenada, sin fines de semana, poco sueldo" (p.10). En esencia, no es como se ha especulado en la literatura, es un trabajo con consideración a las opiniones contrarias que promueve la pluralidad. Los tres autores del libro coinciden en que se iniciaron a una edad adulta en el periodismo. Juan Carlos Tafur referencia que: "Federico Salazar fue el contacto. Su papá, Arturo, era el director de La Prensa, desde el 80, cuando devuelven los periódicos a sus legítimos propietarios" (p.17) Es la empresa periodística la que abrió las puertas y le permitió iniciarse en el periodismo, donde no fue recibido con entusiasmo, por el contrario, existía un boicot permanente. Es transcendental la independencia política de los empresarios sobre medios de comunicación para mantener el pluralismo informativo e investigación, pero en esencia es imposible; porque despiden constantemente a los directores por conservar esa independencia. Es común en los tres autores del libro contar con una profesión ajena al periodismo, como el caso de Juan Carlos Tafur quien es psicoanalista: “Inclusive viví un año como acompañante terapéutico o 'amigo calificado' de un paciente esquizofrénico. Él tenía 38 años y yo 23. Acababa de egresar" (p.21) En la misma línea se ubica Rosa María Palacios, quien revela que su interés giraba en torno a la política peruana, por lo que estudió derecho; aunque la fascinación por el periodismo la inicia muy tarde: "Todos los elementos que sirven para ser periodista estaban ahí, pero yo no lo veía. Luego pasó esa famosa anécdota con Pedro Salinas y Jaime de Althaus, que he contado tantas veces. Expreso había logrado formar un canal de cable..." (p.26)

La segunda parte del libro se refiere a "Compitiendo entre nosotros y padeciendo a los propietarios" y gira en torno a la competencia de Juan Carlos Tafur como director de Correo y Álvarez Rodrich director de Peru.21: "En la definición de la portada, con el equipo de cierre, siempre especulábamos qué iba a poner mañana en su portada el hijo de puta de Tafur [risas]. Cuando él dejó Correo la competencia ya fue mucho más sencilla” (p.35) En relación a los tres autores del libro, Rosa María fue amiga personal de los dos compañeros de trabajo dentro de esa competencia. La intromisión de los gerentes empresariales era una constante en sus trabajos, lo cual reconocen que dificulta la independencia periodística, y de igual forma interfería en las críticas mordaces a los presidentes de turno; así presionaban a Tafur: "Él me decía: 'Haz lo que quieras, pero no te olvides de que yo soy dueño del papel y de la tinta' [risas]" (p.43). Este incidente demuestra que el buen periodismo se torna difícil de realizar en las condiciones previstas de la interferencia gerencial. Por otro lado, los autores establecen discrepancias marcadas entre el periodismo escrito y la televisión, avizoran el futuro de los medios de 
comunicación que están en un explícito proceso de caducidad, porque están dedicándose a repetir noticias de: "China y Rusia, atropellos, choques, volteadas, ¿qué puede tener de noticioso eso? Nada. Absolutamente nada. No sucede acá, es lejano, es ajeno, pero lo pasan y lo pasan y lo pasan" (p.60). Este tipo de supuesta noticia va a hartar al público y no funcionará en el tiempo.

Carlos Tafur testifica que: "En la época de Fujimori, del 90 al 92, yo hacía periodismo en Arequipa, pero allá el Gobierno central no importaba nada. Mi rival era Lucho Cáceres Velásquez [risas]” (p.63). Una apreciación evidente del centralismo peruano que se manifiesta hasta la actualidad, así lo establece en el capítulo "Sufrir gobiernos.” Agrega que Henry Pease le atribuyó el título de "el ideólogo del 5 de abril" en su libro Los años de la langosta, por sus artículos críticos al Congreso. Los autores analizan la importancia de las empresas periodísticas en el ejercicio de la profesión. Álvarez Rodrich referencia a: "Ben Bradley, el legendario director del Washington Post cuando se publicó Watergate, decía que para hacer un gran diario se necesitaba un gran propietario, y él lo decía porque tenía la suerte de tener a Kay Graham" (p.67). Por otro lado, los tres autores coinciden sobre las presiones que reciben de los gerentes para favorecer a ciertos candidatos y defender a personajes polémicos de la política peruana, como lo indica Rosa María: “... la familia Miró Quesada cometió un error editorial. Tenían esta obsesión: si Humala ganaba era el fin del planeta, y no entendían que no era el fin del planeta, nada iba a pasar" (p.70). Así pauteaban las líneas editoriales de los medios de comunicación más importantes del Perú.

La relación interpersonal de amistad se entremezcla en el ejercicio periodístico, afirma Álvarez Rodrich: “Con algunos, la relación se distanció y hasta agrió, como con Pablo Macera, cuando fue candidato al Congreso, y le hice una entrevista para la revista Debate... terminó cuando fue candidato del fujimorismo, y desde entonces ya no lo he vuelto a ver" (p.77); así lo define en el capítulo "Amistades peligrosas" del libro en reseña, en el que afirman que una vez dejado el puesto periodístico nunca más vuelven a llamar; porque existen relaciones conflictivas en defensa de un determinado político de turno. Rosa María Palacios recuerda las relaciones de amistad con políticos: "Con Pedro Pablo Kuczynski tengo una relación muy especial porque, finalmente, lo entrené para el debate y lo he ayudado en algunas ocasiones que me han pedido mi opinión, por amor a la patria” (p.88). La relación profesional dista de las amistades con los personajes que representan a una idea política en el Perú. 
El poder económico es determinante en la concentración de medios de comunicación que excluye la independencia y la objetividad de la investigación: "Durante la Revolución Francesa se acuñó el término 'cuarto poder' para referirse a los medios de comunicación" (Serrano, 2013, p.66). Sería el medio que vigilaría a los tres poderes del Estado, con el pasar del tiempo esos tres poderes son amenazados por el poder económico. Carlos Tafur reconoce: "En la radio, el ministro de Transportes es una vaca sagrada; casi no se le puede tocar, porque de él depende si te quita o no la licencia" (p.98). El asunto de la concentración de medios se redunda en el capítulo “¿Transformación, extinción o concentración?”. Dentro de las preocupaciones por la interferencia en los contenidos editoriales, también está la publicidad y el número de ventas del periódico en físico. Para Rosa María Palacios es importante la posición del director: "Si han visto Game of Thrones, el director periodístico es como Hodor. Es el que se para delante de la puerta y aguanta a todos los demonios detrás" (p.107). Es forzoso el consumo de buen contenido periodístico para la audiencia, de lo contario consumirá subjetividad y banalidad.

Juan Carlos Tafur reflexiona sobre su formación psicoanalista: "Y pensaba que iba a volver la mirada hacia atrás y ver a veinte viejas cojudas curadas por mí [risas]” (p.115), debido a que en el Perú no existe una cultura preventiva y los usuarios puedan pagar una consulta de psicoanálisis. Desde otra perspectiva, los tres autores observan sus inclinaciones periodísticas en el capítulo "De arrepentimientos y otras tristezas". La prensa escrita se va muriendo en las ventas al público lector, y un claro ejemplo de ello es que las personas menores de treinta años no adquieren periódico en los quioscos; según Tafur: "Yo me ponía a pensar si no ocurrió que con Velasco primero y con la crisis de los ochenta después se fue del Perú gran parte de la clase media cultural o intelectualmente activa" (p.120). A esta crisis se suma los puestos de trabajo para tantos egresados profesionales de periodismo en el Perú.

La deontología profesional es determinante en el ejercicio de un trabajo, así analizan los autores en el capítulo de “QQué límites tenemos?” Aquí reflexionan sobre los túneles de la embajada japonesa, Tafur: "Hay que recordar que en esos momentos había una pugna mediática, liderada por Expreso y por La República, para ver si el Estado debía transar y brindar o no una salida negociada. Expreso sostenía que no y La República que sí" (p.129). Son los límites que aíslan a un trabajo ético, enumeran una serie de casos como los de Alan García, Carlos Raffo, Raúl Diez Canseco, el Seguro Social y otros. A esta observación se suma el capítulo “¿Y dónde queda la verdad?”, donde Álvarez Rodrich explica que: "Hace poco leía una entrevista a Juan Soto Ivars, un escritor y columnista español que ha escrito el libro Arden las redes, quien comenta que 'antes de las redes sociales no éramos tan conscientes de que había 
tanta gente con mierda en la cabeza"' (p.157). Las redes sociales son un fenómeno mundial que inserta a la juventud a una vivencia en tiempo real: "En ese sentido, la posverdad resulta no ser un tema aislado en la realidad peruana puesto que las redes sociales favorecen a la proliferación de esta práctica" (Coquis, 2019). La interrelación de información de políticos y población es tergiversada, así lo define Rosa María Palacios: “Así es, pero no estás engañando, es decir, no ocultas la verdad dolosamente; ni sabiendo cuál es la verdad publicas lo contrario - eso ya es un escándalo-, como sucede ahora, en la era de la posverdad" (p.160)

Los autores finalizan el diálogo del libro con el capítulo "Esas cosas raras que te pasan en el periodismo", los extravagantes anecdotarios del periodismo como indica Tafur: "A ver, me llama el director de una agencia en Miami que había tomado la foto de Raúl Diez Canseco con su novia...Me llama y me las ofrece. Mil quinientos dólares por las fotos, eran veinte fotos más o menos. Lamentablemente, en esa época Correo estaba en crisis" (p.165). Son las circunstancias de trabajo para publicar primicias y titulares que den impacto a la empresa periodística. El trabajo se interpone con las amistades y extravagancias, como indica Rosa María Palacios: "Pero bueno, ¿cosas extravagantes para un periodista? Entrenar a PPK para el debate, ¿no?” (p.169). La complicidad de los periodistas es evidente en el debate presidencial con Keiko Fujimori, incluida la invitación de Gustavo Gorriti, como lo devela Rosa María. En este mismo capítulo, Álvarez Rodrich enfatiza el levantamiento armado de Antauro Humala en Andahuaylas y su intermediación en su rendición: "Yo le dije: 'Ollanta, acá hay un problema; el diario que dirijo, Perú.21, es muy opositor de Toledo, va a parecer raro que yo llame a Palacio de Gobierno para decir: Hello, miren lo que tengo que contarles"” (p.176). Parecen gajes del oficio periodístico en estas situaciones decisorias en la política peruana, pero refleja la realidad.

A manera de conclusión, el libro Fuera del aire merece una lectura detenida para conocer el juego periodístico en el interior de las empresas de comunicación nacional monopolizadas; el fenómeno que aflora a la sociedad peruana es maquillado con la supuesta imparcialidad, que en esencia se parcializa con ciertos políticos de su simpatía. Los diarios despiden constantemente a sus directores periodísticos por mantener una línea editorial acorde a sus intereses económicos empresariales. Además, en este libro se evidencia la manipulación de desatapes periodísticos de investigación a favor de unos y en desmedro de otros que no concuerdan con sus intereses ideológicos que en esencia son económicos. Los miles de usuarios que consumen a diario los medios de comunicación en el Perú tienen el deber de analizar la esencia que maquilla el fenómeno noticioso. 


\section{Referencias}

Coquis, D. (2019). La posverdad en el Perú. Punto seguido. Recuperado de https://puntoseguido.upc.edu.pe/la-posverdad-en-el-peru/

Hinojosa, N. G. (2014). Periodismo y propaganda en el Perú. Una relación compleja durante los procesos electorales. Correspondencias \& Análisis, pp. 283. DOI: https://doi.org/10.24265/cian.2014.n4.13

De Moraes, D. (2013). Medios, poder y contrapoder: de la concentración monopólica a la democratización de la información. Buenos Aires, Argentina: Editorial Biblos. Recuperado de https://elibro.net/es/ereader/bibliotecaunah/78553?page=66. 